Discussion Papers in

Economics and Econometrics

2000

This paper is available on our website http://www/soton.ac.uk/ econweb/dp/dp00.html 


\title{
The Relative Dynamics of Investment and the Current Account in the G7-Economies
}

\author{
Mathias Hoffmann ${ }^{1}$ \\ Department of Economics \\ University of Southampton \\ Highfield, Southampton SO17 1BJ \\ United Kingdom \\ E-Mail: mh12@soton.ac.uk
}

March 18, 2000

\footnotetext{
${ }^{1}$ This paper is based on the fourth chapter of my Ph.D. dissertation at the European University Institute, Florence. I am very grateful to Mike Artis, Søren Johansen, Katarina Juselius, Jim Nason, Paolo Paruolo, Axel Weber and Mark Taylor for many comments and discussions. I would also like to thank seminar participants at the Conference 'The Monetary Transmission Mechanism' in Trondheim, the Econometrics Summer Workshop at Humboldt University and at the University of Manchester.
} 


\begin{abstract}
This paper contributes to the empirics of the intertemporal approach to the current account. We use a cointegrated VAR framework to identify permanent and transitory components of country-specific and global shocks. Our approach allows us to empirically investigate the sensitivity to persistence implied by many forward-looking models and our results shed new light on the excess volatility of investment encountered by Glick and Rogoff (JME 1995). In G7 data, we find the relative currentaccount and investment response to be in line with the intertemporal approach.
\end{abstract}

JEL classification: F41, F43

Keywords: Intertemporal Approach to the Current Account, Cointegration, Excess Sensitivity, Investment 


\section{Introduction}

The 'intertemporal theory of the current account' pioneered by Sachs (1981), Obstfeld (1986) and canonized in Obstfeld and Rogoff (1996) is by now a theoretical workhorse in international macroeconomics. Empirical tests of this theory (Gosh (1995) and Sheffrin and Woo (1990)) have generally focused on the reduced-form implications of the linearquadratic present-value model of the current account (PVMCA).

Surprisinlgy, however, very few contributions have moved on to examine the strong predictions of the intertemporal theory with respect to the differential roles of country-specific and global shocks. Notable exceptions to this rule include the leading paper by Glick and Rogoff (1995)and the study by Nason and Rogers (1999). Whereas Nason and Rogers (1999) examine the mutual consistency of various identification schemes in a bivariate vector autoregression of investment and the current account, Glick and Rogoff explore the joint dynamics of the same two variables in an estimable, linearized version of the PVMCA. Both papers concentrate on the joint dynamics of investment and the current account. This focus can be explained in the light of the as yet unsettled debate about Feldstein and Horioka's (1980) savings-investment puzzle. Since Feldstein and Horioka's (1980) seminal paper, essentially two branches of the literature have emerged: one interprets the robust positive correlation of savings and investment (or alternatively: the fairly low correlation between investment and the current account) as indication of the de-facto separation of national capital markets. The other strand theoretically rationalizes positive savings-investment correlations in models that feature perfect capital mobility.

This paper takes the study by Glick and Rogoff (1995), henceforth 'GR' as a point of departure. Their findings are of paramount importance for the empirics of the intertemporal approach. Whereas they show that mainly country-specific shocks drive the dynamics of the current account they also encounter a puzzle: theoretically, the current account should overshoot investment (with opposite sign) in response to permanent country-specific shocks because people will want to invest more and save less in anticipation of increased permanent output. In G7 data, however, GR find that the current account reacts less than investment in response to country-specific shocks. Even though they show that this dynamics can be rationalized once country-specific total factor productivity shocks are allowed to be very persistent but mean reverting, their theoretically elegant solution poses a methodological problem for the empirical researcher: in typical macroeconomic sample sizes it is impossible to statistically distinguish between a near-random walk and an actual unit-root process. 
This is where the present paper steps in: our approach identifies the permanent and transitory components of country-specific and global shocks in a bi-variate cointegrated system rather than specifying them a-priori, outside the econometric model. We find econometric evidence for the excess sensitivity to persistence that GR suggested as a solution to the puzzle. However, in our empirical specification, we also find the current account generally to be more sensitive to permanent countryspecific shocks than investment - in line with the theory. A possible reconciliation of our results with GR's is that the responses estimated in GR are an amalgam of responses to permanent and transitory shocks. This solution to the puzzle has been suggested by GR themselves and is similar in spirit to Quah's (1990) solution to the 'excess-smoothness of consumption' puzzle, but it has to our knowledge not been empirically explored.

The remainder of this paper is structured as follows: in section two we present the model of Glick and Rogoff (1995) and discuss in more detail the puzzle they encountered. In section 3 we will introduce our own approach. We suggest how to estimate permanent and transitory shocks as well as global and country-specific shocks from the data. Section 4 presents data and estimation results and section 5 concludes.

\section{The Glick and Rogoff puzzle}

Glick and Rogoff (1995) linearize an intertemporal model with quadratic utility and adjustment costs in investment to derive the following estimable equations:

$$
\Delta I_{t}=\left(b_{1}-1\right) I_{t-1}+b_{2} \Delta A_{t}^{c}+b_{3} \Delta A_{t}^{w}+v_{I t}
$$

and:

$$
\Delta C A_{t}=c_{1} I_{t-1}+c_{2} \Delta A_{t}^{c}+c_{3} \Delta A_{t}^{w}+r C A_{t-1}+v_{C A t}
$$

In the above, $I$ denotes investment, $C A$ is the current account and $\mathbf{v}_{t}^{\prime}=\left[v_{I t} v_{C A t}\right]$ is a vector of i.i.d. errors and $r$ is the intertemporal discount factor. The vector $\mathbf{A}^{\prime}=\left[A_{t}^{c} A_{t}^{w}\right]$ contains country-specific and global total factor productivities (TFP) that follow an $A R(1)$ process:

$$
\mathbf{A}_{t}=\left[\begin{array}{cc}
\rho_{G R} & 0 \\
0 & 1
\end{array}\right] \mathbf{A}_{t-1}+\left[\begin{array}{c}
e_{t}^{c} \\
e_{t}^{w}
\end{array}\right]
$$

where $e^{\prime}=\left[e^{c} e^{w}\right]$ is the vector of global and country-specific shocks.

Glick and Rogoff show that $v_{C A t}$ is correlated with $C A_{t-1}$ whereas $I_{t-1}$ is predetermined in the equation for $\Delta C A_{t}$. They solve this problem by imposing a value for $r$. Then the system of equations (1) and (2) 
can be estimated by two stage least squares as a seemingly unrelated regression model.

It is an important result of Glick and Rogoff that the coefficient on $\Delta A_{t}^{w}$ in the $C A$-equation is found to be insignificant for all seven countries. This is in accordance with the theory which predicts that the current account should react predominantly to country-specific shocks. In response to global shocks all countries would like to change their current account position into the same direction. As world current accounts sum to zero, the gap between world aggregate savings and investment is closed by adjustments in the world real rate of interest. This process leaves national current accounts unaffected.

However, GR's empirical implementation reveals a puzzle:

Under the assumption that country-specific shocks do have a permanent effect on output, the theory also predicts that $\left|c_{2}\right| / b_{2}>1$, i.e. the reaction of the current account to country-specific shocks should be stronger than the response of investment. A positive, permanent country-specific TFP-shock increases today's gross output, $Y_{t}$. Future gross output will however even be higher than today's gross output because the productivity shock makes it profitable to invest. Hence the future capital stock and consequently also future output will be higher. Because consumption instantaneously adjusts to the permanently higher future output stream, this implies that savings will have to fall and hence the current account should change by more than investment (in the opposite direction, though).

From the data, Glick and Rogoff consistently find estimates of $c_{2}$ that are smaller in absolute value than those for $b_{2}$. This is puzzling but this result strongly depends on the persistence of country-specific shocks. Glick and Rogoff show that even for small deviations of $\rho_{G R}$ from unity, the relative current-account / investment response can be substantially muted: as the country -specific shock does no longer have a permanent component, people will save more instead of less. At the same time, the incentive to invest is weakened as productivity will only be temporarily high and adjustments in the capital stock are costly. Glick and Rogoff show that for reasonably chosen parameter values of the structural model the $C A / I$ response will fall into the range provided by their estimates.

Even though theoretically elegant, the solution suggested by Glick and Rogoff leaves the empirical researcher in a dilemma: in typical macroeconomic sample sizes it is impossible to distinguish between a unit-root process and a near-random-walk. Using univariate time-series properties, it is therefore impossible to assess whether the solution proposed by Glick and Rogoff can actually explain the puzzle.

In the following section, we outline an alternative approach that re- 
lies on measuring the relative importance of transitory and permanent components in country-specific shocks rather than specifying it a priori, as in equation (3) which requires shocks to be fully permanent or fully transitory. Our approach leads to an alternative solution of the Glick-Rogoff puzzle: if shocks have both permanent and transitory components, the estimated response in the Glick-Rogoff model may be an amalgam of responses to permanent and transitory shocks.

Even though this solution - similar in spirit to the one proposed by Quah (1990) for the 'excess-smoothness of consumption' puzzle - has also been suggested by Glick and Rogoff (1995), it has to our knowledge not been explored in empirical research.

\section{A structural VAR of the current account and in- vestment}

In our modelling approach we sacrifice some structure vis-a-vis the Glick and Rogoff specification. This allows us to identify permanent and transitory components of country-specific and global shocks instead of having to specify them a priori. As we will see,this contributes to our solution of the puzzle. The starting point of our analysis is a simple VAR approximation of the joint dynamics of the current account and investment:

$$
\Pi(\mathbf{L}) \mathbf{X}_{t}=\varepsilon_{t}
$$

where $\mathbf{X}_{t}^{\prime}=\left[C A_{t}, I_{t}\right], \varepsilon_{t}$ is the error term with mean zero and covariance matrix $\Omega$ and $\Pi(\mathbf{L})$ is a $2 \times 2$ matrix polynomial in the lag operator.

We follow the structural VAR literature in assuming that the structural, i.e. country-specific and global shocks we are interested in linearly map into the reduced form errors $\varepsilon_{t}$ :

$$
\varepsilon_{t}=\mathbf{S e}_{t}
$$

Requiring that country-specific and global shocks are contemporaneously uncorrelated and have unit variance, we get

$$
\Omega=\mathbf{S S}^{\prime}
$$

To recover the matrix $\mathbf{S}$, we need one more restriction that has to come from theory.

The intertemporal approach to the current account predicts that, conditioning on the past, global shocks do not have an impact on the current account. Glick and Rogoff found this prediction confirmed by their estimates and we employ it here as a just-identifying restriction. 
Consider the moving average representation of $\Delta \mathbf{X}_{t}$ :

$$
\Delta \mathbf{X}_{t}=\mathbf{C}(\mathbf{L}) \varepsilon_{t}=\mathbf{C}(\mathbf{L}) \mathbf{S e}_{t}
$$

In the above, $\mathbf{C}(\mathbf{L})$ is again a matrix polynomial in the lag operator. Then, bearing in mind that $\mathbf{C}(\mathbf{0})$ is the identity matrix, requiring that global shocks do not have an impact on the current account amounts to requiring that $\mathbf{S}$ is lower triangular:

$$
\mathbf{S}=\left[\begin{array}{cc}
s_{11} & 0 \\
s_{12} & s_{22}
\end{array}\right]
$$

Hence, employing the theory to disentangle country-specific and global shocks results in a very simple identifying restriction: $S$ is nothing else than the lower Choleski factor of $\Omega$.

Whereas there is no way of testing a just-identification scheme in the framework of the VAR model it is applied to, we can test the quality of this stunningly simple identification scheme by using cross-country evidence. We will come back to this below.

\subsection{Permanent components}

In order to identify permanent and transitory components of the structural shocks, we employ another feature of the intertemporal model cointegration. Cointegration is a general property of present value models and the implications of this property for econometric modelling have first been explored by Campbell and Shiller (1987). In the framework of the intertemporal theory of the current account it typically arises from a present value relation of the form

$$
C A_{t}=-\sum_{i=1}^{\infty} r^{-i} E\left(\Delta Y_{t+i}-\Delta I_{t+i}\right)
$$

where $Y$ is GDP. If both $Y$ and $I$ are processes that are integrated of order one, then $C A$ as the discounted sum of their changes will be $I(0)$. For the vector $X_{t}$ this amounts to saying that it is trivially cointegrated with cointegrating vector $\boldsymbol{\beta}^{\prime}=[1,0]$.

We can therefore rewrite the VAR (4) in error correction form:

$$
\Gamma(\mathbf{L}) \Delta \mathbf{X}_{t}=\boldsymbol{\alpha} \boldsymbol{\beta}^{\prime} \mathbf{X}_{t-1}+\varepsilon_{t}
$$

This VECM can be inverted to yield a Beveridge-Nelson-Stock-Watson (BNSW) representation in terms of reduced-form disturbances:

$$
\mathbf{X}_{t}=\mathbf{C}(\mathbf{1}) \sum_{l=0}^{t} \varepsilon_{l}+\mathbf{C}^{*}(\mathbf{L}) \varepsilon_{t}
$$


where $\mathbf{C}^{*}(\mathbf{L}) \varepsilon_{t}$ is a stationary moving average and the first term is the random walk component of the $I(1)$-process $\mathbf{X}_{t}$. As Johansen (1995) has shown, $\mathbf{C}(\mathbf{1})$ has a closed-form representation in terms of the parameters of the VECM:

$$
\mathbf{C}(\mathbf{1})=\boldsymbol{\beta}_{\perp}\left(\boldsymbol{\alpha}_{\perp}^{\prime} \boldsymbol{\Gamma}(\mathbf{1}) \boldsymbol{\beta}_{\perp}\right)^{-1} \boldsymbol{\alpha}_{\perp}^{\prime}=\mathbf{A}_{0} \boldsymbol{\alpha}_{\perp}^{\prime}
$$

where $\boldsymbol{\alpha}_{\perp}, \boldsymbol{\beta}_{\perp}$ are the orthogonal complements of $\boldsymbol{\alpha}$ and $\boldsymbol{\beta}$ respectively. The common trends in the system are given by $\boldsymbol{\tau}_{t}=\boldsymbol{\alpha}_{\perp}^{\prime} \sum_{l=0}^{t} \boldsymbol{\varepsilon}_{l}=\sum \boldsymbol{\eta}_{t}$. where $\boldsymbol{\eta}_{t}=\boldsymbol{\alpha}_{\perp}^{\prime} \varepsilon_{t}$ are the permanent shocks to the system. If we require that permanent and transitory shocks be orthogonal to each other, the transitory shocks are

$$
\xi_{t}=\boldsymbol{\alpha}^{\prime} \Omega^{-1} \varepsilon_{t}
$$

In a bivariate system with one cointegrating relationship, $\eta$ and $\xi$ are unique only up to scalar multiplication. Hence, requiring that both $\eta_{t}$ and $\xi_{t}$ have unit variance gives us the matrix $\mathbf{P}$ that maps $\varepsilon_{t}$ on the vector of permanent and transitory disturbances, $\boldsymbol{\theta}_{t}^{\prime}=\left[\eta_{t}, \xi_{t}\right]$ :

$$
\mathbf{P}=\left[\begin{array}{c}
\left(\alpha_{\perp}^{\prime} \Omega \alpha_{\perp}\right)^{-1 / 2} \boldsymbol{\alpha}_{\perp}^{\prime} \\
\left(\alpha^{\prime} \Omega^{-1} \alpha\right)^{-1 / 2} \boldsymbol{\alpha}^{\prime} \Omega^{-1}
\end{array}\right]
$$

Using $\varepsilon_{t}=\mathbf{S e}_{t}$, we are now in a position to identify permanent and transitory components of country-specific and global shocks. The matrix that maps global and country-specific shocks into the permanent and transitory domain is given by

$$
\boldsymbol{\theta}_{t}=\mathbf{P S e}_{t}=\mathbf{Q e}_{t}
$$

Note that $\mathbf{Q}=\mathbf{P S}$ is orthonormal, i.e. $\mathbf{Q Q}^{\prime}=\mathbf{I}_{n}$.

Note that due to the unit variance of the components of $\mathbf{e}_{t}$ and $\boldsymbol{\theta}_{t}$, the elements of $\mathbf{Q}$ are the cross-correlations of $\mathbf{e}_{t}$ and $\boldsymbol{\theta}_{t}$. Figure (1) gives a geometric illustration: $\mathbf{Q}$ defines a rotation of the orthogonal basis of the country-specific and global shocks onto the basis of permanent and transitory shocks. The upper left entry of $\mathbf{Q}$ which we will henceforth denote by $\rho$, is nothing else than the cosine of the angle $\lambda$ between the typical country-specific shock and the permanent axis, the span of $[0, \eta]^{\prime}$. As the space of orthonormal $(2 \times 2)$ matrices is one-dimensional, the parameter $\rho$ uniquely determines $\mathbf{Q}$.. This becomes immediately apparent from recalling that $\mathbf{Q Q}^{\prime}=\mathbf{I}$, which imposes 3 non-redundant restrictions on $\mathbf{Q}$. We can then parametrize $\mathbf{Q}$ as a function of the permanent component of country-specific shocks as follows:

$$
\mathbf{Q}(\rho)=\left[\begin{array}{cc}
\rho & -\sqrt{1-\rho^{2}} \\
\sqrt{1-\rho^{2}} & \rho
\end{array}\right]=\left[\begin{array}{cc}
\cos \lambda-\sin \lambda \\
\sin \lambda & \cos \lambda
\end{array}\right]
$$


We deliberately choose $\rho$ to denote the permanent components of country-specific shocks, in analogy to $\rho_{G R}$ in section 2. Certainly, these are not the same parameters but in the context of different models they formalize the same notion: $\rho$ measures the correlation between the country-specific and the permanent shock in the VAR, whereas $\rho_{G R}$ roughly measures the conditional correlation between $A_{t}^{c}$ and $A_{t-1}^{c}$. In this sense, both $\rho$ and $\rho_{G R}$ are persistence measures.

\subsection{The Current Account - Investment Response}

As opposed to Glick and Rogoff's model, our framework allows structural shocks to have both transitory and permanent components. Hence, the parameter $\rho$ introduced above and $\rho^{G R}$ in (3) are not the same. In spite of these differences, translating the GR results into our framework appears obvious: The analogue of their estimates of $b_{1}, b_{2}, c_{1}$ and $c_{2}$ in our model is given by the matrix $\mathbf{S}=\left\{s_{i j}\right\}$. The GR puzzle - that the current account reacts less than investment in response to a country-specific shock - would therefore amount to estimates of $\mathbf{S}$ such that $\left|s_{11}\right|<s_{12}$.

The focus of our interest is the relative impulse response of the current account and investment, $\chi=s_{11} / s_{21}$, and how it relates to $\rho$. It is therefore useful to express $\chi$ and $\rho$ as functions of the VAR-parameters.

Let the elements of the reduced-form residual covariance matrix be given by $\Omega=\left\{\omega_{i j}\right\}$. Then, recalling that $S$ is just the lower Choleski Factor of $\Omega$, we get

$$
\mathbf{S}=\left[\begin{array}{cc}
\sqrt{\omega_{11}} & 0 \\
\omega_{21} / \sqrt{\omega_{11}} & \sqrt{\omega_{22}-\omega_{21}^{2} / \omega_{11}}
\end{array}\right]
$$

Then,

$$
\chi=\frac{s_{11}}{s_{21}}=\frac{\omega_{11}}{\omega_{21}}
$$

We can also get a closed-form representation for $\rho$. Let $\boldsymbol{\alpha}^{\prime}=\left[\alpha_{1}, \alpha_{2}\right]$ and recall that $\mathbf{Q}=\mathbf{P S}$

Then, with $\boldsymbol{\alpha}_{\perp}^{\prime}=\left[-\alpha_{2}, \alpha_{1}\right]$ one obtains

$$
\rho=\frac{-\alpha_{2} \sqrt{\omega_{11}}+\alpha_{1} \omega_{21} / \sqrt{\omega_{11}}}{\sqrt{\alpha_{2}^{2} \omega_{11}+a_{1}^{2} \omega_{22}-2 \alpha_{1} \alpha_{2} \omega_{21}}}
$$

Furthermore, it will prove useful to bear in mind that the correlation of the reduced-form innovations in the current account and investment is given by:

$$
\phi=\frac{\omega_{21}}{\sqrt{\omega_{11} \omega_{22}}}
$$


Note that whenever $\rho=1$. we can solve (13) to find that

$$
\phi= \pm 1
$$

This is an important first result: if country-specific shocks are completely permanent, we should expect changes in the current account and investment to be perfectly correlated. This explains why Glick and Rogoff - like many other authors - find a robust negative correlation that is, however, significantly different from one. Complete persistence of country-specific shocks would make the matrix $\boldsymbol{\Omega}$ singular, which is another way of stating that investment and the current account have a 'common cycle'.

It is also noteworthy to see what happens once $\rho=0$. From (13) we find that

$$
\chi=\frac{s_{11}}{s_{21}}=\frac{\omega_{11}}{\omega_{21}}=\frac{\alpha_{1}}{\alpha_{2}}
$$

This, in fact, provides a simple way to test the null that $\rho=0$ : we just have to test $\omega_{11} / \omega_{21}=\alpha_{1} / \alpha_{2}$ which boils down to a simple t-test on the coefficient on the current account in the conditional model:

$$
\Delta I=\frac{\omega_{21}}{\omega_{11}} \Delta C A_{t}+\left(\alpha_{2}-\frac{\omega_{21}}{\omega_{11}} \alpha_{1}\right) \boldsymbol{\beta}^{\prime} \mathbf{X}_{t-1}+\widetilde{\Gamma(L)} \Delta \mathbf{X}_{t-1}
$$

where $\widetilde{\Gamma(L)}=\boldsymbol{\Gamma}(\mathbf{L})_{I}-\omega_{21} \boldsymbol{\Gamma}_{C A}(\mathbf{L}) / \omega_{11}$ and $\boldsymbol{\Gamma}_{C A}(\mathbf{L})$ denotes the first row of $\boldsymbol{\Gamma}(\mathbf{L})$ and $\boldsymbol{\Gamma}_{I}(\mathbf{L})$ the second.

Furthermore, for sufficiently small estimates of $\rho$, we can interpret $\alpha_{1} / \alpha_{2}$ as the 'shadow' impulse response, i.e. the impulse response that we would observe if country-specific shocks were just persistent but had no permanent component. This gives us an empirical approximation of the excess-sensitivity of the impulse response that GR have justified on theoretical grounds.

\section{Empirical results}

\subsection{Data and model specification}

In the estimation of our model, we used the data given in the appendix of Taylor (1996): annual savings and investment rates for the G7-countries (Unites States, Japan, Germany, France, Italy, the United Kingdom and

\footnotetext{
${ }^{1}$ This is just a dual way of phrasing the Feldstein-Horioka puzzle: if changes in the current account actually represent changes in investment then the covariance between savings and investment changes will be zero.As long as country-specific shocks are not completely permanent, however, we should see some correlation between saving and investment, even under perfect capital mobility. In theoretical terms, this insight has first been put forward by Obstfeld $(1986,1995)$.
} 
Canada) from 1960 to 1991 . We then used the real GDP data in Gordon (1993) to convert the rates into levels.

As our data are not exactly the same as GR's, we have to ascertain that their properties are by and large the same. In table 1 we therefore report the starting point for GR's paper: the results of a simple regression of changes in the current account on changes in investment. The estimates are all between zero and negative unity and typically very close to the values found by Glick and Rogoff.

In a first step, we estimated an unrestricted VAR in levels to determine the correct lag length of the VAR model. Hannan-Quinn-, Schwarzand Akaike information criteria all suggested that one to two lags yielded an adequate representation of the data for all seven countries. To allow for richer dynamics, we chose two lags for all models.

In our estimation we included a set of exogenous regressors to take account of factors that the small open economy model abstracts from: for the UK and Canada we included the price of crude oil and the Can\$/US\$ exchange rate respectively.For the G3 economies, i.e. the US, Japan and Germany, we found bilateral short-term nominal interest rate differentials to be highly correlated with changes in the current account. Using the short-term nominal interest rates from Gordon (1993), we therefore conditioned the G3-models on the interest differential vis-a-vis the US (vis-a-vis Germany for the US).

Recent work by Harbo et al. (1998) has established that the distributions of tests for cointegrating rank in systems with weakly exogenous regressors can be substantially altered vis-a-vis the standard distributions that arise when the partial system is treated as if it was a full system. Hence, our systems for the G3 and the UK and Canada should be regarded as two-dimensional subsystems of three-dimensional systems where we assume that the conditioning variable does not react to the cointegration error ${ }^{2}$. Using the crital values from table 3 in Harbo et al. (1998) for those five countries and the conventional critical values for France and Italy, table 2 shows that we can reject the null of no cointegration in all seven countries.

In table 3 we report the tests of the restriction $\boldsymbol{\beta}^{\prime}=[1,0]$ on the cointegrating space. Except for Germany, we find that it is indeed the current account that is stationary. For Germany, we found $\boldsymbol{\beta}^{\prime}=[1,1 / 2]$ to be accepted by the data and we decided to estimate the German

\footnotetext{
${ }^{2}$ As this assumption is potentially violated for the nominal interest rate differential in the models for the G3, we checked it in a tri-variate system containing investment, the current account and the short-term interest differential. For all three countries we found one cointegrating relationship and the interest rate differential was found not to react to the cointegration error.
} 
model with this cointegrating vector imposed. Note that while the simple PVMCA suggests that $\boldsymbol{\beta}^{\prime}=[1,0]$, our reasoning in the previous section does not depend on any particular value for $\boldsymbol{\beta}$. In particular, as can be seen from (13), $\rho$ depends only on the variance-covariance structure and on the vector $\boldsymbol{\alpha}$ of adjustment coefficients.

\subsection{How country-specific are country-specific shocks?}

Before we discuss the impact of various degree of persistence for the relative dynamics of the current account and investment, we should recall that our identification procedure for country-specific shocks relied on the theory itself. Even though our theoretical presumption is backed by the results of Glick and Rogoff, some kind of assessment of how well this just-identifying procedure works is called for. There is clearly no way in which we can evaluate a just-identifying assumption within each individual model. However, we have valuable information in the crosssection of countries we are investigating. The G7 countries account for two thirds of world output and they represent a fairly closed bloc in the world economy. It therefore seems reasonable to take these countries as a proxy of the 'rest of the world'. Country-specific shocks should then be uncorrelated across countries whereas we should find some correlation between the global shocks identified at the country level.

Table 4 gives the average correlation of each country's specific and global shocks with all other 6 countries. It also provides the (crosssectional) standard errors of these correlations. The result is very encouraging: not only are global shocks much more highly correlated across countries than country-specific shocks, their correlation is also highly significant. On the other hand, country-specific shocks are on average not significantly correlated. The only exception is Canada, where both country-specific shocks and global shocks are on average significantly correlated with shocks in the rest of the world. Still, these results should provide some confidence that by and large we have indeed identified the right shocks.

\subsection{Discussion of the results}

The first column of table (5) provides the estimates of the permanent components of country-specific shocks. As the sign of $\rho$ does not matter for our purposes, we report $\rho^{2}$ for all G7 countries. This gives us the added benefit that $\rho^{2}$ can be interpreted as the share of permanent shocks in the variability of the country-specific shocks.

Overall, country-specific shocks in the G7 do not appear to have large permanent components. There are however, a few exceptions: For Japan, 38 percent of the variability in the country-specific shock seems to 
be explained by permanent influences and for Germany even 86 percent.

One clear result stands out: country-specific shocks are neither fully permanent nor completely transitory: On average, 23 percent of the variance of country-specific shocks is explained by permanent influences.

The second column of table (5) provides the relative impulse response of the current account and investment, $\chi$. Contrary to the results obtained by GR, the current account generally overshoots investment. The exceptions to this rule are the US where the $C A$-response is still just half of the investment response and Italy, where the $C A$-response amounst to roughly 80 percent of the $I$-response. On average, however, the current account response is 1.23 times stronger than the investment response.

Finally, the third column of table (5) gives the shadow-response of investment and the current account that would prevail if country-specific shocks were only transitory, i.e. $\alpha_{1} / \alpha_{2}$ : here, the current account response would generally be weaker than the response of investment, in line with the theoretical solution proposed by Glick and Rogoff. These results provide an empirical corroboration of the excess sensitivity of the intertemporal model with respect to the persistenceof shocks.

Table (5) suggests an alternative solution to the GR puzzle: countryspecific shocks are predominantly transitory but have small permanent components. These permanent components lead the current account to respond more sensitively to country-specific shocks than investment, in accordance with the theory.

In order to secure this point, we need to take account of the uncertainty involved in the estimation of the model: once we fix the impulse response to a value smaller than minus unity, we must be able to reject that $\rho=0$, whereas we should not be able to reject this null when conditioning on a relative impulse response that is larger than minus unity. These tests can be conducted in the framework of the following equation:

$$
\Delta I_{t-1}=a \Delta C A_{t}+b \boldsymbol{\beta}^{\prime} \mathbf{X}_{t-1}+\mathbf{g}(\mathbf{L}) \Delta \mathbf{X}_{t-1}
$$

From (16) above, the true values of $a$ and $b$ and $\mathbf{g}(\mathbf{L})$ are $\omega_{21} / \omega_{11}=$ $1 / \chi,\left(\alpha_{2}-\alpha_{1} \omega_{21} / \omega_{11}\right)$ and $\widetilde{\Gamma}(\mathbf{L})$ respectively. This gives the conditional model of investment given the current account. Tests of the null $b=0$ then amount to tests of $\rho=0$.

We estimated (17) under two different restrictions: first, we restricted $a$ to the inverse of our estimate of the relative impulse response, i.e. $1 / \chi$. Then we restricted it to the inverse of the shadow impulse response, i.e. $\alpha_{2} / \alpha_{1}$. In both cases we then tested $b=0$. Table (6) gives the results.

For all countries except the US and Italy, we find that $b=0$ is heavily rejected whenever we fix $a$ to $1 / \chi$, whereas we do generally accept $b=0$ if $a=\alpha_{2} / \alpha_{1}$. 
Whereas for Italy the puzzle seems to persist, note that for the US we found. that $|\chi|<1$. Given that we accept $b=0$ in the case of $a=1 / \chi$, the relative impulse response of the US current account and investment actually turns out to be in line with the theory. Here, the theoretical solution proposed by GR seems to work: country-specific shocks are not completely permanent and the relative impulse response gets muted.

Our results so far were obtained in a model framework that differs markedly from the one chosen by Glick and Rogoff. To check that our results are independent from the particular model setup chosen, we use the country-specific and global shocks we identified from the cointegrated VAR as regressors in the GR model ${ }^{3}$. Table 7 shows the results of this exercise. Again, for most countries the current account reacts stronger than investment to country-specific shocks. The UK and Italy are borderline cases and the only country where marked undershooting occurs are the US which is in line with the theory once we bear in mind that in this country the country-specific shock is found not to have a permanent effect. Note also that even with our different set of shocks, the current account response to global shocks is insignificant, again in line with the GR findings and the theory.

\section{Conclusion}

In a landmark paper, Glick and Rogoff (1995) empirically demonstrated that mainly country-specific shocks matter for current account dynamics. Their results are very persuasive because they derive a directly estimable econometric system from first principles. However, when confronted with the data, their model produces an open-economy version of the 'excess-smoothness of consumption' puzzle. The authors offer a rationalization for this: if country-specific shocks follow a near-random walk, the relative response of the current account can be substantially muted. While theoretically elegant, this way of rationalizing the puzzle poses an empirical dilemma because in typical macroeconomic sample sizes it is impossible to distinguish between random walks and near random walks.

In the present paper, we started from a reduced form cointegrated VAR and we identified global and country-specific shocks using restrictions from the theory. This framework allows for both permanent and transitory components and enables us to conduct a reduced-form sensitivity analysis. We generally find evidence for the excess sensitivity implied by the intertemporal model: The current account is generally more

\footnotetext{
${ }^{3}$ The structural shocks are generated regressors and OLS will be inefficient but consistent in this case (Pagan (1984), Hoffmann (1987)). As Hoffman's (1987) indicator did not signal large generated regressor biases, we did OLS.
} 
sensitive to permanent country-specific shocks than investment and in most countries we find that country-specific shocks do have small permanent components. Conversely, our estimates of shadow-impulse responses suggest that the relative current account - investment response gets muted to below unity if country-specific shocks are merely transitory but persistent. Our results seem to suggest that the responses estimated in GR (1995) are an amalgam of responses to permanent and transitory shocks. In theoretical terms this rationalization has first been suggested by Quah (1990) in a closed-economy setting. It has also been mentioned by Glick and Rogoff (1995) themselves. However, to date, no effort has been made to empirically explore it.

Even though our results focus on a relatively tiny aspect of the intertemporal approach, we think they are important as intertemporal models of the current account are increasingly becoming the workhorses of international macroeconomics.

\section{References}

[1] Beveridge, S. and Nelson, C. R., (1981), 'A New Approach to the Decomposition of Economic Time Series into Permanent and Transitory Components with Particular Attention to the Measurement of the Business Cycle,' Journal of Monetary Economics 7: 151-74.

[2] Campbell, J. Y, and Shiller, R.J., (1987), ' Cointegration and tests of present value models,' Journal of Political Economy, 95: 10621088.

[3] Feldstein, M. and Horioka, C., (1980), 'Domestic Saving and International Capital Flows', Economic Journal 90: 314-329.

[4] Ghosh, A., (1995), 'Capital mobility amongst the major industrialized countries: Too little or too much?,' Economic Journal 105: $107-128$

[5] Glick, R. and Rogoff, K., (1995), 'Global versus country-specific productivity shocks and the current account,' Journal of Monetary Economics 35: 159-92.

[6] Gordon, Robert J., (1993), Macroeconomics, Addison-Wesley. Data set to be found at http://www.nber.org/pub/gordon.

[7] Harbo, I., Johansen, S., Nielsen, B. and Rahbek, A. (1998), 'Asymptotic Inference on Cointegrating Rank in Partial Systems', Journal of Business and Economics Statistics 16: 388-99.

[8] Johansen, S., (1988), 'Statistical Analysis of Cointegrating Vectors', Journal of Economic Dynamics and Control, 12:231-54.

[9] Hoffman, D. L. (198), 'Two-Step Generalized Least Squares Estimators in Multi-Equation Generated Regressor Models', The Review of Economics and Statistics, 69 (2): 336-346. 
[10] Nason, J. and Rogers, J. (1999), 'Investment and the Current Account in the Short Run and the Long Run', Discussion paper no. 647, Board of Governors of the Federal Reserve System, Washington D.C.

[11] Obstfeld, M., (1986), 'Capital Mobility in the World Economy: theory and measurement', Carnegie Rochester Conference Series on Public Policy 24: 55-104.

[12] Obstfeld, M., (1995), 'International Capital Mobility in the 1990s' in Kenen, P. (ed.) Understanding Interdependence, Princeton University Press, 1995.

[13] Obstfeld, M. and Rogoff, K. (1995), 'The intertemporal approach to the current account,' NBER working paper 4893.

[14] Obstfeld, M. and Rogoff, K., (1996), Foundations of International Macroeconomics, MIT Press, Cambridge.

[15] Pagan, A. (1984), 'Econometric Issues in the Analysis of Regressions with Generated Regressors' International Economic Review, 25 (1): 221-247.

[16] Penati, A. and Dooley, M., (1984), 'Current Account Imbalances and Capital Formation in Industrial Countries 1949-81', IMF Staff Papers 31: 1-24.

[17] Quah, D. (1990), 'Permanent and transitory movements in labor income: an explanation for "Excess Smoothness" in Consumption', Journal of Political Economy 98: 449-75.

[18] Sachs, J, (1981), 'The Current Account and Macroeconomics adjustment in the 1970s,' Brookings Papers on Economic Activity 1:201-268.

[19] Sheffrin, S. and Woo, W. T. (1990), 'Present Value Tests of an Intertemporal Model of the Current Account' Journal of International Economics 29: 237-53.

[20] Taylor, A. M., (1996), 'International Capital Mobility in History: The Saving-Investment Relationship', NBER Discussion Paper Series, no. 5743 


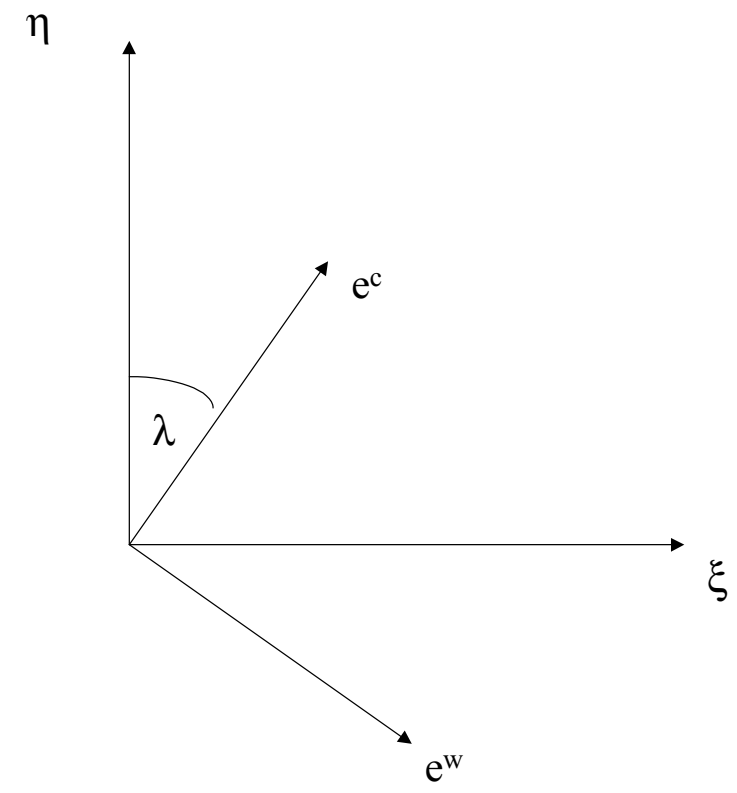

Fig.1: The geometry of global and country-specific shocks 
Table 1: OLS time series regression of the current account on investment 1960-91

\begin{tabular}{cccccccc}
\multicolumn{6}{c}{ Regression $\Delta C A=a+b \Delta I+v_{t}$} \\
\hline & US & Japan & Germany & France & Italy & UK & Canada \\
\hline$b$ & $\mathbf{- 0 . 2 1}$ & $\mathbf{- 0 . 2 9}$ & $\mathbf{- 0 . 2 6}$ & $\mathbf{- 0 . 4 1}$ & $\mathbf{- 0 . 6 0}$ & $\mathbf{- 0 . 5 5}$ & $\mathbf{- 0 . 2 7}$ \\
& $(0.05)$ & $(0.07)$ & $(0.09)$ & $(0.08)$ & $(0.06)$ & $(0.08)$ & $(0.12)$ \\
\hline \multicolumn{7}{c}{ standard errors in parantheses }
\end{tabular}

Table 2: Tests for cointegration

a) Johansen Trace statistic

\begin{tabular}{|c|c|c|c|c|c|c|c|c|c|}
\hline & 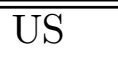 & "Japan & Germ & France & Italy & 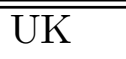 & Canada & $90 \%$ & $95 \%$ \\
\hline$h=0$ & 25.4 & 25.06 & 20.78 & 19.58 & 19.57 & 14.29 & 13.82 & 15.58 & 17.84 \\
\hline$h=1$ & 4.85 & 0.02 & 0.12 & 2.84 & 1.137 & 2.13 & 3.07 & 6.69 & 8.08 \\
\hline \multicolumn{10}{|c|}{ b) Johansen Maximum Eigenvalue statistic } \\
\hline & US & Ja & $\overline{\mathrm{Gel}}$ & Frai & Italy & $\overline{\mathrm{UUK}}$ & $\overline{\mathrm{Ca}}$ & $90^{\circ}$ & $95 \%$ \\
\hline & 20.55 & 25.04 & 20.66 & 16.73 & 18.43 & 12.16 & 10.74 & 12.78 & 14.6 \\
\hline$h=1$ & 4.85 & 0.02 & 0.12 & 2.84 & 1.137 & 2.13 & 3.07 & 6.69 & 8.08 \\
\hline
\end{tabular}

The tests were performed on VAR(2)-models with an unrestricted constant. The models for the US, Japan, Germany, the UK and Canada.

included one weakly exogenous regressor. Critical values for the trace test, following table 3 in Harbo et. al. in this case are 10.4 (12.3) at 90 (95)\%.

Table 3: Estimates of the cointegrating vector

Estimate of $\beta=\left[1 \beta_{2}\right]$ and test of $H_{0}: \beta_{2}=0$

\begin{tabular}{llllllll}
\hline \hline & US & Japan & Germany & France & Italy & UK & Canada \\
$\beta_{2}$ & -0.2535 & 0.0174 & $\mathbf{- 0 . 6 1 9}$ & -0.002278 & -0.005234 & 0.1728 & 0.0883 \\
$L R$-test & 1.91 & 0.2482 & 12.8 & 0.005503 & 0.0113 & 1.04 & 2.27 \\
$P$-value & 0.17 & 0.62 & 0.0003 & 0.94 & 0.92 & 0.6922 & 0.13
\end{tabular}


Table 4: Cross-country correlations of structural shocks

a ) country-specific shocks $\left(e^{c}\right)$

\begin{tabular}{|c|c|c|c|c|c|c|c|}
\hline & $\overline{\mathrm{US}}$ & Japan & Germany & France & Italy & UK & Canada \\
\hline avg & 0.00731 & 0.1112 & -0.04689 & 0.08786 & 0.1378 & 0.02057 & -0.1623 \\
\hline stan & 0.02016 & 0.07102 & 0.0 & 0.0 & 0.07629 & 0.0 & 637 \\
\hline \multicolumn{8}{|c|}{ b) global shocks $\left(e^{w}\right)$} \\
\hline & US & Japan & Germ & Fra & Italy & UK & Canada \\
\hline avg. & 0.2136 & 0.2842 & 0.217 & 0.3556 & 0.2025 & 0.2802 & 0.1658 \\
\hline standard dev. & 0.03877 & 0.04214 & 0.03662 & 0.01577 & 0.0401 & 0.009901 & 0.06059 \\
\hline \multicolumn{8}{|c|}{$\begin{array}{l}\text { The average correlation is } \gamma_{i}^{k}=\frac{1}{6} \sum_{j=1, j \neq i}^{7} \operatorname{corr}\left(e_{i}^{k}, e_{j}^{k}\right) k=w, c \text { and the cross-sectional } \\
\text { standard deviation is } \sigma_{\gamma i}^{k}=\frac{1}{5} \sum_{j=1, j \neq i}^{7}\left(\operatorname{corr}\left(e_{i}^{k}, e_{j}^{k}\right)-\gamma_{i}^{k}\right)^{2}\end{array}$} \\
\hline
\end{tabular}

Table 5: Permanent Components, relative impulse responses and shadow impulse responses

\begin{tabular}{lcll} 
VAR: $\rho$ and impulse responses \\
\hline Country & $\rho^{2}$ & $\chi$ & $\frac{\alpha_{1}}{\alpha_{2}}$ \\
US & 0.17 & -0.51 & -1.4 \\
Japan & 0.38 & -1.64 & -0.59 \\
Germany & 0.87 & -1.8 & -0.29 \\
France & 0.10 & -1.29 & -0.79 \\
Italy & 0.05 & -0.8 & -0.75 \\
UK & 0.05 & -1.02 & -0.83 \\
Canada & 0.03 & -1.48 & 0.75 \\
\hline Average & 0.23 & -1.23 & -0.54
\end{tabular}


Table 6: Test of $\rho=0(b=0)$ in the conditional model

\begin{tabular}{lrr}
\multicolumn{3}{c}{$\Delta I_{t-1}=a \Delta C A_{t}+b \beta^{\prime} X_{t-1}+g(L) \Delta X_{t-1}$} \\
t-values \\
Restriction: & $a=1 / \chi$ & $a=\alpha_{2} / \alpha_{1}$ \\
\hline US & 0.39 & -0.61 \\
Japan & 10.20 & -0.36 \\
Germany & 90.81 & -1.40 \\
France & 5.20 & 0.05 \\
Italy & 8.09 & -0.39 \\
UK & 9.09 & -0.64 \\
Canada & -12.39 & 0.03 \\
\hline
\end{tabular}

Table 7: Estimation of the GR-model with country-specific and global shocks identified from the VAR

\begin{tabular}{|c|c|c|c|c|c|}
\hline & $\Delta Z$ & $b_{1}$ & & $b_{2}$ & \\
\hline \multirow[t]{2}{*}{$\overline{\mathrm{US}}$} & $\triangle C A$ & 0.06 & $(0.011)$ & 0.000 & $(0.016)$ \\
\hline & $\Delta I$ & -0.11 & $(0.016)$ & 0.022 & $(0.002)$ \\
\hline \multirow[t]{2}{*}{ Japan } & $\triangle C A$ & 0.65 & $(0.106)$ & 0.005 & $(0.035)$ \\
\hline & $\Delta I$ & -0.48 & $(0.184)$ & 0.33 & $(0.061)$ \\
\hline \multirow[t]{2}{*}{ Germany } & $\triangle C A$ & 0.08 & $(0.007)$ & 0.00 & $(0.005)$ \\
\hline & $\Delta I$ & -0.05 & $(0.017)$ & 0.07 & $(0.013)$ \\
\hline \multirow[t]{2}{*}{ France } & $\triangle C A$ & 0.04 & $(0.006)$ & 0.00 & $(0.003)$ \\
\hline & $\Delta I$ & -0.03 & $(0.009)$ & 0.02 & $(0.005)$ \\
\hline \multirow[t]{2}{*}{ Italy } & $\triangle C A$ & 0.14 & $(0.018)$ & 0.02 & $(0.026)$ \\
\hline & $\Delta I$ & -0.16 & $(0.028)$ & 0.14 & $(0.042)$ \\
\hline \multirow[t]{2}{*}{ UK } & $\triangle C A$ & 0.27 & $(0.019)$ & 0.04 & $(0.017)$ \\
\hline & $\Delta I$ & -0.28 & $(0.025)$ & 0.22 & $(0.022)$ \\
\hline \multirow[t]{2}{*}{ Canada } & $\triangle C A$ & 0.28 & $(0.014)$ & -0.006 & $(0.011)$ \\
\hline & $\Delta I$ & -0.15 & $(0.022)$ & 0.23 & $(0.018)$ \\
\hline
\end{tabular}

